$\begin{array}{ll} & \text { Etnográfica } \\ \text { etnográfica } & \text { Revista do Centro em Rede de Investigação em }\end{array}$

Antropologia

vol. $22(2) \mid 2018$

Vol. $22(2)$

\title{
Urbanismo utópico, realidades distópicas: una etnografía (im)posible en Yachay, "ciudad del conocimiento"
}

Utopian urbanism, dystopian realities: an (im)possible ethnography in Yachay, the City of Knowledge

Miquel Fernández González, Maribel Cadenas Álvarez y Thomas Purcell

\section{(2) OpenEdition}

\section{Journals}

Edición electrónica

URL: https://journals.openedition.org/etnografica/5474

DOI: 10.4000/etnografica.5474

ISSN: 2182-2891

\section{Editor}

Centro em Rede de Investigação em Antropologia

Edición impresa

Fecha de publicación: 1 junio 2018

Paginación: 335-360

ISSN: 0873-6561

Referencia electrónica

Miquel Fernández González, Maribel Cadenas Álvarez y Thomas Purcell, «Urbanismo utópico, realidades distópicas: una etnografía (im)posible en Yachay, "ciudad del conocimiento"», Etnográfica [En línea], vol. 22 (2) | 2018, Publicado el 07 julio 2018, consultado el 19 enero 2022. URL: http:// journals.openedition.org/etnografica/5474 ; DOI: https://doi.org/10.4000/etnografica.5474

\section{(c) (1) (8)}

Etnográfica is licensed under a Creative Commons Attribution-NonCommercial 4.0 International License. 


\section{Urbanismo utópico, realidades distópicas: una etnografía (im)posible en Yachay, "ciudad del conocimiento"}

\section{Miquel Fernández González, Maribel Cadenas Álvarez y Thomas Purcell}

Descrito como el proyecto más importante en la historia del Ecuador, Yachay, que significa conocimiento en quechua, es una iniciativa de desarrollo urbano concebido como el puente hacia una sociedad que no dependa de la naturaleza. Abrazando la actual ola de optimismo que rodea a las plataformas de código abierto de intercambio de información, Yachay se ha proyectado como un nuevo "paraíso del conocimiento". Se trata de la utopía de una nueva ciudad que transforme un país basado en una economía extractiva en otro basado en el conocimiento y las nuevas tecnologías. El riesgo de perseguir este sueño es el ignorar las condiciones económicas y políticas existentes, pero también las esperanzas de construir "un país nuevo" que trajo consigo la así llamada Revolución Ciudadana. Quisimos pensar, reflexionar y aprender sobre uno de los planes urbanísticos más emocionantes que han surgido en América Latina. Este artículo informa sobre los intentos frustrados para llevar a cabo la investigación e interpreta los elocuentes silencios y renuencias de los responsables de este macroproyecto urbanístico.

PALABRAS-CLAVE: Yachay, Ecuador, etnografía censurada, participación ciudadana, smart cities.

Utopian urbanism, dystopian realities: an (im)possible ethnography in Yachay, the City of Knowledge - Described as the most important project in Ecuador's history, Yachay, meaning knowledge in Kichwa, is an urban development initiative conceived as the bridge towards a society free from the dependent exploitation of nature. Embracing the current wave of optimism that surrounds open-source platforms of information sharing, Yachay has been projected as a new "knowledge heaven." This is the utopia of a new city converting a society based on an extractive economy into one based on knowledge. The risk of pursuing this dream is ignoring the existing economic and political conditions but also the hopes to build a "new country" that the so-called Citizen Revolution brought about. We wanted to think, reflect and learn about one of the most thrilling urban plans to have emerged in Latin America. This paper reports on frustrated attempts to conduct this research and interprets the eloquent silences and reluctance of those responsible for this urban macroproject.

KEYWORDS: Yachay, Ecuador, censured ethnography, citizen participation, smart cities.

FERNÁNDEZ GONZÁLEZ, Miquel (miquel.fernandez@uab.cat) - Universitat Autònoma de Barcelona, España. 
CADENAS ÁLVAREZ, Maribel (maribel@wewearbuildings.cc) - Universitat Rovira i Virgili, España.

PURCELL, Thomas (thomas.purcell@outlook.com) - Leeds Beckett University, Gran Bretaña.

\section{INTRODUCCIÓN}

La "ciudad del conocimiento" Yachay se está construyendo desde 2012 en Ecuador y ha sido declarada como proyecto emblemático del gobierno de la Revolución Ciudadana. Se sitúa en el municipio de San Miguel de Urcuquí, provincia de Imbabura, a 20 kilómetros de Ibarra, su capital, y a 180 kilómetros al norte de Quito. Ocupa una superficie de 4489 hectáreas sobre terrenos agrícolas altamente productivos. Su nombre, Yachay, significa conocimiento en la lengua quechua. Lo que hace del proyecto Yachay único, dada la proliferación global de las llamadas "ciudades del conocimiento" (Saha y Sen 2016; Baqir y Kathawala 2004), es el doble énfasis del plan puesto en el urbanismo participativo, comunitario e inclusivo bajo la bandera del "buen vivir" y la prosecución de una versión post-neoliberal de competitividad sistémica. ${ }^{1}$ La idea es aprovechar la biotecnología y producir mediante ella un espacio hiper-moderno de diseño urbano que debería llevar a la substitución de la matriz productiva extractivista de Ecuador hacia una basada en la producción de conocimiento y alta tecnología (Macías Vázquez y Alonso González 2016).

Otro interés particular del estudio de esta nueva ciudad resulta de la contradicción semántica de llamar Yachay a una ciudad construida desde cero en terrenos muy productivos y cimentarla alrededor de una universidad tecnológica de fuerte inspiración capitalista y, por tanto, depredadora (el modelo de Yachay Tech es el del Massachusetts Institute of Technology). La contradicción se manifiesta al reconocer que la tradición indígena de donde proviene la expresión yachay la define como:

"Un proceso dinámico que implica añadir, agregar y completar lo que nos hace falta. Añadimos y agregamos lo que contiene la tierra (de los animales, vegetales, minerales y astros y de las personas). De ellos heredamos poderes para desarrollar la fuerza, la armonía, sabiduría, habilidades

l Competitividad sistémica: concepto acuñado por investigadores europeos que provee de un nuevo marco teórico para analizar qué factores estimulan u obliteran dinámicas de desarrollo industrial (Esser et al. 1996). 
y sentido comunitario, mediante el acto recíproco de ofrecer y recibir (rituales, prácticas espirituales) con el fin de obtener personas Eanas 'sabios' (inteligentes, lúcidos)" (Marcos Yule 1999: 6, citado en Castillo Collado 2005: 102).

Pues bien, en esta nueva ciudad se ha instalado la Universidad de Investigación de Tecnología Experimental Yachay Tech, que abrió sus puertas el 31 de marzo de 2014. Allí se están construyendo, además institutos públicos y privados de investigación, centros de transferencia tecnológica, y se prevé la instalación de empresas de alta tecnología y de la comunidad agrícola y agro-industrial de Ecuador. ${ }^{2}$

Teníamos la intención de realizar una etnografía sobre la participación ciudadana en Imbabura, escogiendo como caso de estudio paradigmático Yachay, e implementarla con un análisis urbanístico de la ideación, planificación y construcción de esta nueva ciudad. Aunque conseguimos realizar unas primeras aproximaciones al campo de estudio, muy pronto se nos fue vetado el acceso, la observación y las entrevistas a personas involucradas o afectadas por la construcción de esta ciudad.

En este artículo exponemos los principales resultados de nuestra investigación, que hemos articulado de la siguiente manera: primero, compartimos nuestra reflexión metodológica, que creemos fundamental, puesto que se nos negó a realizar nuestra investigación, teniendo que replantearla en función de este inaudito rechazo; proseguimos con el debate conceptual a propósito de las utopías espaciales y algunas de sus contradicciones; por último, la parte central expone nuestro análisis sobre la cuestión urbanística y explica el rechazo a la participación ciudadana y el resto de agravios que está suponiendo la construcción de esta ciudad para los habitantes y trabajadores de la zona.

El objetivo de este artículo es demostrar cómo la utopía tecnócrata que representa "la primera ciudad planificada del Ecuador" está tentada a ignorar la sociedad civil y denostar el pensamiento crítico. ${ }^{3}$ Sólo partiendo de que Yachay aspira a ser una utopía practicada se puede comprender la paradoja de una "participación ciudadana" inexistente y la actitud de recelo por parte de sus gestores ante cualquier investigación crítica sobre el proyecto.

2 En mayo de 2017, cinco años después de su inauguración, el website oficial de Yachay informa que se han instalado dos empresas: un pequeño departamento de la filial ecuatoriana de la empresa IBM, Cloud and Mobile Open Space, y Athos, una empresa mediana con sede en São Paulo (Brasil) y dedicada al software de gestión empresarial.

3 "Yachay [...] es la primera ciudad planificada del país", se dice en el website oficial de Yachay, $<$ www.yachay.gob.ec > (última consulta en junio de 2018). Obviamente, no ha sido la primera ciudad planificada - Quito o el mismo Ibarra fueron claramente ciudades planificadas por los colonizadores españoles del siglo XVII. 


\section{UNA METODOLOGÍA PARADÓJICA PARA EXPLICAR EL RECHAZO} A CONOCER LA CIUDAD DEL CONOCIMIENTO

Etnografiar la construcción de Yachay, "la primera ciudad planificada" del Ecuador, representaba para nosotros una oportunidad única: estudiar el sueño histórico de muchos urbanistas y sociólogos urbanos, una ciudad de nueva planta, desde su conceptualización hasta su cristalización y en un contexto sociopolítico muy particular, el de la llamada Revolución Ciudadana, la cual define los parámetros de la transformación que pretende Ecuador desde la elección de Rafael Correa como presidente de la República en 2007. ${ }^{4}$ Una ola de participación popular y optimismo político dio pie a la elaboración de la nueva Constitución de Montecristi, en 2008, el lanzamiento en 2009 del segundo Plan Nacional para el Buen Vivir (PNBV), además de un nivel sin precedentes de inversión en educación e investigación dirigida por la Secretaria Nacional de Educación Superior (Senescyt) para crear la nueva sociedad del Sumak Kawsay. ${ }^{5}$ Así pues, el proyecto Yachay se sitúa en la cúspide de esta estrategia, deviniendo emblema de la transformación nacional.

Estas páginas son el resultado de una etnografía que ha intentado censurarse. Con ella queríamos registrar la ideación, construcción y participación ciudadana del megaproyecto urbanístico Yachay; en otras palabras, la materialización de lo que se promocionaba como "la ciudad del Buen Vivir". ${ }^{6}$ La información aquí expuesta la hemos obtenido a pesar y en contra del Estado ecuatoriano. Los funcionarios del gobierno con los que nos hemos topado durante nuestra estancia académica en Ecuador han hecho todo lo posible para que investigadores, avalados por sus mismas instancias

4 El equipo de investigación estaba formado por el coordinador Miquel Fernández González (socioantropólogo), Maribel Cadenas (urbanista i antropóloga) y Thomas Purcell (economista).

5 El "Buen Vivir" es una propuesta política que procede del concepto quechua sumak kawsay, que significa "buen vivir" o "vida plena", en el sentido de vida armónica colectiva entre los seres humanos y con la naturaleza. El esperanzador Plan Nacional para el Buen Vivir es un documento que procura establecer los objetivos del desarrollo de la nación ecuatoriana. En su presentación se define el "Buen Vivir" como "la forma de vida que permite la felicidad y la permanencia de la diversidad cultural y ambiental; es armonía, igualdad, equidad y solidaridad. No es buscar la opulencia ni el crecimiento económico infinito" (Senplades 2013: 13). En su edición de 2013-2017, tiene como objetivo número uno "Consolidar el Estado democrático y el poder popular [y] fomentar la participación política y la organización social" (Senplades 2013: 17). Para ello cuentan "además de los instrumentos previstos en la Carta Magna, la promulgación de la Ley Orgánica Electoral-Código de la Democracia (2009) y de la Ley Orgánica de Participación Ciudadana (2010)" (Senplades 2013: 96). Elaborado por la Secretaría Nacional de Planificación y Desarrollo (Senplades), de nueva creación, en su primera edición, para 2007-2010, "se origina[va] en el proyecto político de cambio que planteó la Revolución Ciudadana. Este documento se convierte en la hoja de ruta que termina con la improvisación y la visión cortoplacista que ha imperado en las políticas públicas" (website oficial, en $<$ http://instrumentosplanificacion.senplades.gob.ec/plan-nacional-de-desarrollo $>$, última consulta en junio de 2018).

6 Ver < www.yachay.gob.ec > (última consulta en junio de 2018). 
educativas, ${ }^{7}$ no pudieran conocer la "ciudad del conocimiento". Se desplegaron una serie de estrategias para bloquear nuestros esfuerzos de investigación: la indiferencia a las solicitudes de información, la interferencia con nuestros métodos de investigación, la vigilancia de nuestro trabajo y el cuestionamiento de nuestra ética profesional. Esto culminó en la negativa pura y simple de acceso al campo para realizar entrevistas y observaciones in situ. Incluso se nos amenazó con la aplicación de "procedimientos disciplinarios internos". Esto se producía al mismo tiempo que se pretendía impedir la publicación o comunicación de esta situación en el ámbito académico.

Evidentemente, estos impedimentos modificaron nuestro primer objetivo de etnografiar la concepción y diseño de una nueva ciudad. Haciendo de la necesidad virtud, hemos convertido esta imposibilidad de conocer y compartir conocimiento en uno de los temas principales de la etnografía. Giramos e implementamos las preguntas de investigación alrededor de la producción de conocimiento y, en este caso, las dirigimos a las siempre fecundas paradojas en sociología (Estradé 1986) para preguntarnos bajo qué pretextos se nos impedía conocer la "ciudad del conocimiento". Nos propusimos entonces inventariar la literatura académica sobre Yachay. Esta primera tarea nos puso sobre la pista de más contradicciones. Sorprendentemente, frente a la abundante producción de textos, imágenes y vídeos promocionales, a día de hoy sólo existen dos artículos científicos sobre la construcción de la nueva ciudad. ${ }^{8}$

Por todo ello, consideramos necesario focalizar la investigación sobre la participación ciudadana en Yachay e implementarla con un análisis urbanístico. Esta ciudad de nueva planta devenía el caso de estudio indudablemente más significativo del presente imbabureño, si no ecuatoriano. Para el análisis urbanístico, planteamos un trabajo de campo etnográfico siguiendo la línea de investigaciones realizadas en estudios de diseño urbano sobre el proceso de proyectar edificaciones o barrios enteros (Degen, Melhuish y Rose, 2015; Halpern et al. 2013), es decir, hacer observación participante en el departamento de arquitectura y urbanismo competente y realizar visitas de obra, además de realizar grupos de discusión y entrevistas a las personas implicadas en

7 El investigador principal del proyecto, Miquel Fernández González, estaba vinculado al Proyecto Prometeo de la Secretaria Nacional de Educación Superior, Ciencia, Tecnología e Innovación (Senescyt); Thomas Purcell era, en el momento de la investigación, el subdirector del Cenedet, centro nacional para estrategias del derecho al territorio, dependiente del Instituto de Altos Estudios Nacionales, Quito, Ecuador. La investigadora Maribel Cadenas estaba realizando una estancia académica en la UTN (Universidad Técnica del Norte), gracias a una beca de la AUIP (Asociación Universitaria Iberoamericana de Posgrado).

8 En las búsquedas a través de las bases de datos de artículos científicos apenas aparecen dos publicaciones. Se trata de una nota del urbanista Michael Sorkin, uno de los invitados al think tank celebrado en Yachay en el 2013, publicada en una revista de arquitectura y titulada "Learning from Yachay" (Sorkin 2014), y de un texto sobre qué significa la construcción Yachay en los debates sobre "neodesarrollismo y postdesarrollismo" (Macías Vázquez y Alonso González 2016). 
el proyecto. Al mismo tiempo, nos propusimos realizar observación no intrusiva en la parte de ciudad que ya estaba construida y funcionando, la de la universidad Yachay Tech, y recoger datos sobre los usos, prácticas, relaciones sociales, apropiaciones y resignificaciones de los espacios que se estaban dando por parte de estudiantes, profesores, trabajadores y visitantes.

Este artículo propone una primera hipótesis según la cual existe una correlación positiva entre estos macroproyectos urbanísticos y la práctica institucional tanto de la censura como del regateo de las leyes y el control social a la que deben someterse según la reciente aprobada Constitución. En otras palabras, aquí mostramos un ejemplo paradigmático de uno de los requisitos para proyectos urbanísticos de este tipo y es que - debido a diversos motivos que exponemos a continuación - no permiten ser participativos ni analizados críticamente.

En tanto investigadores se nos vetó y persiguió nuestra indagación, al parecer, para que no descubriéramos los severos errores de planificación, la escandalosa falta de participación o la vulneración de derechos constitucionales. En el caso concreto de nuestro objeto de estudio, esta experiencia de siete meses intentando conocer la "ciudad del conocimiento" nos permite proponer una segunda hipótesis relativa al precio que se está pagando por perseguir esta utopía, como es el abandono de los principios rectores de la Revolución Ciudadana propuestos en el Plan Nacional del Buen Vivir y protegidos por la Constitución ecuatoriana de 2008.

A partir de este momento, adoptamos la postura de autores como James Clifford (1988), quien afirmó que la tarea del etnógrafo es la de desacreditar la "fábula del informe neutro" y enfrentar las contradicciones entre el observador, el encargado de realizar la investigación, y los grupos humanos concernidos en ella. Por otro lado, el etnólogo Michel Leiris proclamó a mediados del siglo pasado que "nos corresponde [a los etnógrafos] ser como sus abogados naturales [los de las sociedades colonizadas] frente a la nación colonizadora [...] tenemos que tomar en todo momento la posición de defensores de estas sociedades y de sus aspiraciones" (Leiris 1995: 38, traducción libre). Con estas premisas, y a pesar de que las circunstancias han dificultado un análisis más concreto y prolífico, hemos producido datos significativos relativos a la planificación urbanística y ejecución de este proyecto emblemático que aspira a transformar el país.

\section{DEBATE CONCEPTUAL: YACHAY EN TANTO UTOPÍA ESPACIAL}

Henri Lefebvre (1976) nos enseñó que las utopías de los planificadores urbanísticos pretenden una cosificación del espacio para convertirlo en una malla donde intervenir de manera científica y neutra con vistas a la consecución de un objetivo. En este caso, la misión encomendada a Yachay consiste en la 
transformación de una zona agrícola en una "ciudad del conocimiento" para solucionar gran parte de los problemas sociales y económicos de Ecuador. A este principio David Harvey (2009: 110) lo define como "utopías de la forma espacial". 9 El espacio, que siempre ha sido político y estratégico, pasa a mistificarse para, entre otras cosas, inocular el derecho de sus habitantes a permanecer en él en las condiciones que ellos acuerden.

$Y$ es que, frente a lo que comprobamos como una experiencia de destrucción del territorio, ${ }^{10}$ desahucio habitacional y laboral de poblaciones subalternas y campesinas, incumplimientos de la Constitución y displicencias en cuanto al cumplimiento de los objetivos del PNBV, la visión utópica se impone como un muro incontestable. Ésta envuelve el proyecto en su totalidad hasta el punto de que podría definirse como mesiánico y redentor. ${ }^{11}$ En la inauguración del primer curso académico de Yachay, el presidente evocó "El gran salto adelante", arquetípico de la Revolución China, pero, al mismo tiempo, distanciándose de él en lo que respecta a "la lucha de clases y la búsqueda del lucro individual".

“[Rafael Correa afirmó que] La ciencia, la tecnología y la innovación son fundamentales para el desarrollo... creo en el poder transformador de la ciencia y la tecnología. En ese poder deposito gran parte de mi esperanza en el futuro del planeta, en la sostenibilidad de nuestro modo de vida, en la posibilidad de alcanzar el buen vivir para toda la humanidad [...] estoy convencido de que los adelantos científicos y tecnológicos pueden generar mucho más bienestar y ser motores de cambios sociales que cualquier lucha de clases o la búsqueda del lucro individual... Ecuador no está inaugurando edificios, por más bellos que sean, sino conocimiento". ${ }^{12}$

En este sentido, Yachay se inscribe en una narrativa de transformación positiva, en un discurso terapéutico donde se expone "a corrupted past and a

9 En la práctica, la mayoría de las utopías realizadas de forma espacial se han logrado a través de la acumulación estatal o de capital, actuando de común acuerdo y deviniendo la norma (Harvey 2000: 100, 173).

10 Antagónica con los "derechos de la naturaleza" recogidos en la Constitución de 2008, artículos 71 a 74. El primero de ellos estipula: "La naturaleza o Pacha Mama, donde se reproduce y realiza la vida, tiene derecho a que se respete integralmente su existencia y el mantenimiento y regeneración de sus ciclos vitales, estructura, funciones y procesos evolutivos".

11 El titular que ejemplifica mejor esta función que se le atribuye a Yachay es el aparecido en el website de Andes - Agencia Pública de Noticias del Ecuador y Suramérica: "Yachay, ícono de la nueva 'Era del Conocimiento' en Ecuador", 15 de enero de 2015, en < https://www.andes.info.ec/es/noticias/politica/3 /yachay-icono-nueva-era-conocimiento-ecuador > (última consulta en junio de 2018).

12 Ver "Yachay, el salto en la revolución del conocimiento", El Telégrafo, 01 de abril de 2014, en $<$ https://www.eltelegrafo.com.ec/noticias/sociedad/1/yachay-el-salto-en-la-revolucion-del-conocimien to-video $>$ (última consulta en junio de 2018). 
perfect and immutable future - an ideal and universally valid model of society constituted by rational spatial form" (Choay 1997, en Söderström, Paasche y Klauser 2014: 314). Es por ello que el proyecto Yachay se explica como el dispositivo que transformará la "República bananera" en un "paraíso del conocimiento". ${ }^{13}$ Aquello que librará a Ecuador "del neocolonialismo [será] caminar hacia la sociedad del conocimiento, hacia la producción del conocimiento". ${ }^{14}$ La idea de cambiar todo un país con la nueva "ciudad del conocimiento" nos recuerda a la fundación de las capitales modernas del siglo XX. Estas ciudades, construidas también desde cero, se asentaron en una paradoja utópica: un futuro deseado que representa la negación de las condiciones existentes. Esta fue la idea central de la crítica de Holston (1989) a Brasilia, donde el diseño y la construcción de la ciudad no eran sólo un símbolo de una nueva era sino un medio para crearla. Se esperaba que la arquitectura y la planificación urbana a gran escala del movimiento moderno fueran un llamamiento a los gobiernos de todo espectro político del "tercer mundo" a modernizarse, como una "ideología de desarrollo en el que los gobiernos tratan de reescribir la historia nacional" (Holston 1989: 5).

Desde esta conceptualización es útil reflexionar sobre cómo las imágenes y discursos de Yachay, que giran sobre tres vectores fundamentales - tecnología, educación y competitividad -, se presentan de espaldas a las condiciones existentes, es decir: dependencia del petróleo, poca fuerza de trabajo calificada y baja productividad (Villavicencio 2014). Salvar esta fabulosa diferencia es precisamente la contradictoria premisa del proyecto: transformar Ecuador en un país basado en el desarrollo de la alta tecnología cuando las condiciones infraestructurales no lo permiten (Blanco 2013) e intentar llevar a cabo este salto mediante la construcción utópica de una ciudad high tech. Siguiendo a Arturo Villavicencio, Yachay intenta "sostener la ilusión de cambio hacia la hipermodernidad" (2014: 10). Se trata, al fin, de descubrir y hacer rendir políticamente los usos políticos de la utopía. Quizás encontremos en esta contradicción el motivo del afán modernizador del presidente Correa y la paranoia de proteger la imagen de Yachay como el proyecto de desarrollo más importante y ambicioso de la historia del Ecuador.

Nuestra exploración teórica sobre el rechazo a entrar al campo nos puso sobre la pista de trabajos que elucidaban las complejidades de investigar y discutían los dilemas teóricos, consideraciones políticas, peligros y posibles imposiciones éticas durante el trabajo de campo (Hume y Mulcock 2004). Algunos

13 Ver "Looking inside Yachay, Ecuador's new 'city of knowledge'", entrevista de Jared Wade a Héctor Rodriguez en website de Newshore Americas, 09 de deciembre de 2015, en < www.nearshoreamericas. com/yachay/ > (última consulta en junio de 2018).

14 Ver "Presidente: derecha critica a Universidad Yachay para derribar sueño de los jóvenes", El Tiempo, 05 de abril de 2014, en < https:/www.eltiempo.com.ec/noticias/ecuador/4/presidente-derecha-critica-a -universidad-yachay-para-derribar-sueno-de-los-jovenes > (última consulta en junio de 2018). 
se consagraban a estrategias para salvar estos contratiempos (Kovats-Bernat 2002), otros ofrecían una serie de efectos sobre el investigador que suscribimos, como eran la soledad y la voluntad de nuestros superiores de hacernos sentir avergonzados, tristes, deprimidos, traidores al mismo tiempo que traicionados, desesperados, perturbados y asustados (Pollard 2009). El caso en el que nos encontrábamos nos impelía a enfrentar las amenazas institucionales y "to develop creative, public and novel modes of doing imaginative and critical sociological research" (Back y Puwar 2012).

A partir de nuestra reconfiguración del marco conceptual y de la insistencia en impedirnos realizar investigación pública, fundamentamos nuestras dos hipótesis. Se trataba de implementar estas explicaciones sobre las causas y consecuencias de estos impedimentos para entrar al campo y añadir una nueva explicación que correlacionara estas dificultades con los megraproyectos urbanísticos, tal y como contrastan diversas investigaciones (Cunha et al. 2015; Liang 2013; Soares 2010; Box 2003). En este sentido, consideramos que proyectos urbanísticos de esta envergadura requieren negar u obliterar tanto la participación ciudadana como la investigación científica sobre el proceso de planificación y construcción de la nueva ciudad.

\section{RESULTADOS DE UNA ETNOGRAFÍA BAJO CENSURA}

Nuestro primer acercamiento a Yachay fue accidental. Durante nuestra primera estancia en Ecuador, entre los meses de junio y agosto de 2014, realizamos entrevistas con técnicos municipales de participación ciudadana, organizaciones sociales y líderes comunales de los diferentes cantones de Imbabura. ${ }^{15}$ Nos encontrábamos en el Cantón de San Miguel de Urcuquí, desarrollando nuestro trabajo de campo, cuando los técnicos municipales nos explicaron que su mayor problema era el malestar y la inquietud provocada entre los vecinos por la absoluta falta de participación con la que se estaba llevando a cabo la ideación, planificación y construcción de Yachay. Nos advirtieron de las dificultades, las agresiones y los desencantos que les estaba provocando la nueva ciudad.

No fue hasta nuestra primera reunión con los representantes de la empresa pública Yachay EP, encargada de la construcción y gestión de la nueva ciudad, que se nos hizo notar que nuestro papel de investigadores incordiaba. ${ }^{16}$

15 Se trata del proyecto I+D "La ciudad del Buen Vivir: espacio público, transformación social y participación política popular”, que, además, cuenta con el apoyo del proyecto Prometeo 2014-2015, ambos registrados en la Secretaría Nacional de Educación Superior, Ciencia, Tecnología e Innovación (Senescyt) del Gobierno del Ecuador. Finalmente, el proyecto recibió la aprobación de la Universidad Técnica del Norte el 10 de febrero de 2014.

16 Yachay EP es la empresa pública responsable del desarrollo y la gestión de la ciudad del conocimiento Yachay. Fue creada el 13 de marzo de 2013, por el Decreto Ejecutivo 1457. 
En esta reunión, celebrada en mayo de 2015, nos obligaron a proseguir nuestra investigación coordinados por la "Directora de Educación de Yachay EP" y no "entrar en el territorio" hasta firmar un "convenio de confidencialidad" con dicha empresa pública. ${ }^{17}$ Tras aceptar las condiciones, comenzamos a trazar junto a la "coordinadora" impuesta un plan de trabajo de campo que contemplaba entrevistas a los trabajadores de la empresa pública y vecinos de las comunidades, grupos de discusión, talleres participativos y visitas de campo acompañadas por los arquitectos encargados de la ejecución del proyecto. Como intuimos por el trato de recelo recibido desde el primer día, el convenio de confidencialidad nunca llegó, deviniendo una triste y espuria pretensión de legalizar su negativa a que se investigue sobre Yachay. ${ }^{18}$ Debido a nuestra insistencia en la voluntad de investigar la "ciudad del conocimiento", estos datos y su respectivo análisis son ahora públicos.

Por otro lado, esta situación nos obligó a reenfocar nuestro trabajo de tres maneras. Primero, las torticeras estrategias oficiales para impedirnos hablar con los trabajadores de Yachay EP y vecinos de Urcuquí o simplemente observar la vida cotidiana de la nueva ciudad devinieron una información extremadamente elocuente, hasta el punto de convertirse en el material central de nuestra investigación junto con la información proveniente de entrevistas y observación sobre el terreno obtenida antes de la reunión citada. Segundo, esta imposibilidad nos obligó a focalizar la atención en el análisis del material generado por Yachay EP y publicado en su website, siguiendo otros autores en situaciones parecidas (Burrell 2009). Esta exploración fue completada por el estudio comparativo de ciudades contemporáneas "construidas de cero" (Halpern et al. 2013; Phillips 2014; Spann 2014). Y tercero, este rechazo nos llevó a contactar con personas relacionadas con el proyecto, pero elocuentemente desvinculadas de la empresa pública. Fue así como conocimos a los jóvenes arquitectos ecuatorianos - ahora ex-trabajadores de Yachay EP - que participaron en la génesis del proyecto, en la construcción del relato y en los primeros pasos de su cristalización. En sus entrevistas

17 Las razones que la directora de Educación de Yachay EP argumentaba para la prohibición de la "entrada al territorio" se podían resumir en "cuestiones de calidad académica y ética investigadora". Ella mencionaba el cansancio de los sujetos de estudio (vecinos) debido a la gran cantidad de trabajos académicos que, según ella, se estaban realizando sobre la nueva ciudad y a la poca fiabilidad de los datos (incorrectos y sesgados) que obtendríamos del campo si íbamos sin su compañía.

18 Recibimos diferentes e-mails por parte de la "coordinadora" durante los meses de mayo, junio y julio de 2015, en los que anunciaba que el "documento de confidencialidad estaba a punto de ser evacuado". Después de varios meses de espera, y bajo el supuesto que Yachay es una universidad pública, por tanto de acceso libre, la investigadora Maribel Cadenas decidió visitar autónomamente Yachay. Su visita fue registrada y reportada a la "coordinadora" quien le convocó a una reunión urgente en julio en la sede principal de Yachay EP (Quito). En ella le alertó de que había "roto el acuerdo de confidencialidad”. Días antes, Fernández González, había sido amenazado con un "correctivo interno" por parte de Senescyt si no dejaba inmediatamente de investigar "y hablar" sobre Yachay. 
descubrimos - no sin cierta sorpresa - que tras el discurso oficial sobre la ciudad planificada había algo más que pura retórica y promoción. De entre una retahíla de términos que más bien evocaban los lugares comunes y la literatura al uso relativa a las llamadas "smart cities", "ciudades del conocimiento" o "cities from scratch", parecía haber un relato fundador bien armado que encajaba perfectamente con los objetivos del PNBV y con los ideales de la Revolución Ciudadana.

\section{La mirada urbanística sobre los retos y contradicciones de la ciudad planificada}

En 2012, el presidente Rafael Correa aprobaba el concepto de diseño de "La ciudad del conocimiento Yachay". ${ }^{19}$ Los principios de desarrollo hablaban de una ciudad compacta, de uso mixto, caminable, sostenible, eficiente, integrada, de crecimiento inteligente y que potenciaba microeconomías locales que a su vez debían convertirse en los suministradores principales de la nueva ciudad. Estas propuestas fueron entregadas a la firma coreana IFEZ, encargada de la redacción del plan maestro. ${ }^{20}$ En marzo de 2013 se creaba la Empresa Pública Yachay (Yachay EP) y, pocos meses después, se contrataba a los citados jóvenes arquitectos ecuatorianos, la mayoría de ellos influenciados por el nuevo urbanismo, con el encargo de revisar el plan maestro ideado en Corea del Sur por IFEZ y que poco o nada tenía que ver con el original urbanismo del "buen vivir". ${ }^{21}$

En esta nueva etapa se recogieron las aportaciones del think tank celebrado en agosto de 2013 y se "recuperaron muchos elementos que estaban al principio pero que con IFEZ se dañaron", tal y como nos explica uno de los arquitectos entrevistados [arquitecto 2] ${ }^{22}$ El objetivo era "tropicalizar el plan maestro y adecuarlo a la realidad ecuatoriana" [arquitecto 4]. El trabajo conjunto con IFEZ para redefinir la planificación fue "una pugna entre ideologías, entre dos

19 Redactado por un consultor externo. Su modelo de ciudad se basa en el espacio público. El conocimiento se genera a través de las redes comunitarias y la interacción social en el mismo.

20 Incheon Free Economic Zone (IFEZ) fue el primer FEZ (Free Economic Zone) designado en Corea del Sur en agosto de 2003, en un área de 169,5 km2 que comprende el Aeropuerto Internacional de Incheon, el puerto de Incheon, y Songdo, Yeongjong y Cheongna. Más información en <www.ifez. go.kr/eng/ > (última consulta en junio de 2018).

21 El movimiento "new urbanism" surgió en la década de 1990 en los Estados Unidos con el fin de neutralizar las tendencias de diseño urbano que se habían consolidado tras el movimiento moderno, basadas en la ocupación y desarrollo extensivo del territorio. Algunos arquitectos entrevistados se han especializado en este "nuevo urbanismo". También comparten las mismas referencias William H. White, Jane Jacobs, Jan Gehl, Andrés Duany y Jeff Speck.

22 Con el fin de validar la planificación urbana de Yachay, se organizó el think tank "Yachay: city of knowledge, future strategies for developments", donde se invitó a treinta expertos internacionales en temas urbanos. Durante el think tank, el concepto de Yachay fue validado y todos los participantes coincidieron en la necesidad de que "la ciudad debía ser resiliente, transitable, e identificada [...] con el carácter de la zona” [arquitecto 2]. 
modelos de ciudad, una más responsable socialmente, otra de una ciudad de rápida construcción" [arquitecto 4]. ${ }^{23}$ Quedaron sin resolverse algunas controversias importantes relativas a la excesiva zonificación, primacía del coche, baja densidad de las zonas residenciales y falta de integración en el entorno de su primera propuesta. En estas condiciones, IFEZ entregaba el plan maestro definitivo en noviembre de 2013, vaciado de cualquiera de los contenidos iniciales sometidos a los principios del PNBV.

\section{La pugna de dos modelos espaciales}

La colaboración entre IFEZ y los jóvenes urbanistas ecuatorianos fue problemática. Éstos últimos se enfrentaron a una serie de contradicciones "inherentes" al proyecto que intentaron "arreglar de la mejor manera posible" [arquitecto 2]. La primera contradicción versaba sobre el propio hecho de construir una ciudad de cero: "Para solventarla se pensaba siempre en Yachay a una escala regional, como la zona metropolitana de Ibarra" [arquitecto 1]. ${ }^{24}$ "No podemos construir de cero, solución: Nos vamos a [vincular a] Urcuquí y a las comunidades [rurales afectadas]" [arquitecto 3], comentaba otro de los arquitectos, aunque esto "implicaba un proceso más lento de lo que se está haciendo ahora" [arquitecto 1]. En este sentido, comprobamos cómo, durante la cristalización del relato, primó la velocidad y la eficacia, la necesidad de construir rápido (y sin problemas) algo "grande, vistoso". ${ }^{25}$

IFEZ había elegido Urcuquí entre otras localizaciones atendiendo a variables como el clima, la disponibilidad de tierras y agua o la ubicación. Los arquitectos entrevistados ponían en duda la neutralidad de tal elección y afirmaban que "fue una decisión política" [arquitecto 3]. La verdadera razón - como luego expondremos con más detalle - respondía al relativo bajo índice de tenencia de la tierra: "Menos propietarios, menos expropiaciones" [arquitecto 3], el mismo argumento expuesto por el profesor Villavicencio (2016) y que más adelante analizaremos. ${ }^{26}$

23 Según los arquitectos entrevistados, el gobierno de Ecuador contrata IFEZ por su experiencia como "administradores de ciudades aduana" y por su "modelo de hacer ciudad de Songdo". Su modelo se corresponde con el contexto asiático, donde "el crecimiento es exponencial y sin control" [arquitecto 4]. Songdo es una smart city que se está construyendo desde cero en una zona económica libre para atraer la inversión extranjera y nacional (Halpern et al. 2013).

24 Ibarra es la capital de la provincia de Imbabura y cuenta con aproximadamente 150.000 habitantes. 25 "Yachay ya está transformando al Ecuador", decía el presidente Rafael Correa ("Presidente: 'Nadie tocará nuestra Yachay', El Telégrafo, 17 de agosto de 2015, en < http://www.eltelegrafo.com.ec/noticias/ informacion-general/1/presidente-nadie-tocara-nuestra-yachay > (última consulta en junio de 2018).

26 En la entrevista con el abogado de las comunidades sobre el tema de las expropiaciones, descubrimos que los propietarios eran no sólo los grandes propietarios, ya que se expuso en el discurso oficial, pero tenía una proporción significativa de los pequeños y medianos propietarios [abogado]. Se podría decir que IFEZ eligió el lugar más cercano a la "tierra vacía" o "territorio abandonado", donde se recomienda la construcción de FEZ y la "charter city". Ver la ciudad de Songdo, construida sobre [continua] 
Desde Yachay EP se pidió a IFEZ estudios más exhaustivos de la hidrología, topografía, restos arqueológicos... del entorno. "iNo queríamos comenzar a mapear como si fuera un lienzo en blanco, pero los de IFEZ sí, querían ir rápido y que [les] paguen [...] ya!", interpretaba uno de los entrevistados [arquitecto 4]. Las preexistencias físicas, sociales y culturales (canales, acequias, caminos, tolas, asentamientos...) debían marcar el trazado de la trama urbana. ${ }^{27}$ El gran reto consistía en la integración con el entorno: "Siguiendo el PNBV, debía ser una ciudad socialmente integrada, desde lo físico-espacial hasta lo administrativo [...]. Aunque era un proyecto de impacto nacional, lo que queríamos hacer era un plan de integración con los municipios, como una mancomunidad, en beneficio mutuo y con beneficios directos" [arquitecto 1]. En este sentido, se propusieron líneas de desarrollo local basadas, por ejemplo, en la industria del cuero de Cotacachi, la textil de Otavalo o la producción agrícola y gastronómica de Urcuquí [arquitecto 2].

De hecho, el encuentro entre el tejido urbano de las comunidades y la nueva trama urbana de Yachay era un tema que preocupaba a los arquitectos de Yachay EP: ${ }^{28}$ "¿Qué pasará cuando en una pequeña comunidad, las casitas chiquitas con sus pequeños terrenos agrícolas tengan al lado edificios de ocho pisos en un manzana ocupada un $80 \%$ ?" [arquitecto 2]. Es elocuente el hecho que, tanto en los videos promocionales como en la maqueta del plan maestro de IFEZ, las comunidades han sido, literalmente, barridas del mapa. Uno de los entrevistados se mostraba muy crítico:

"no estamos flotando en el éter, estamos en un contexto, en Urcuquí, en Imbabura, en Ecuador. [...] Se podían haber hecho leyes específicas, aprobadas y discutidas en la asamblea, con consulta previa. Tienen todo el apoyo para hacerlo y lo pudieron hacer. Pero no fue nunca una consideración. Han generado desconfianza e inseguridad [entre los vecinos afectados]" [arquitecto 3].

A finales de 2014, ninguno de los arquitectos entrevistados seguía trabajando en Yachay EP. En sus respuestas a la pregunta de por qué no continuaron en el proyecto se repetían las palabras "presiones o decisiones políticas", "estrés", etc... Todos coincidían en afirmar que "lo que se planificó fue muy

terrenos ganados al mar. El ideador del concepto de "charter cities", el economista Paul Romer, explica las razones: es más fácil y más rápido para construir en las ciudades donde la gente no vive, ya que no es necesaria la participación ciudadana y ahorra posibles conflictos sociales y jurídicos (Mackey 2014).

27 Incluso (re)crean un mito fundador de las brujas "para que cuelgue el imaginario de la nueva ciudad". En este caso eran las brujas de Urcuquí, "una vieja leyenda en la zona, nada inventado" [arquitecto 4$]$.

28 Ellos trataron de resolverlo creando zonas de transición entre el tejido rural y el nuevo tejido urbano de Yachay. Utilizaron el "transecto", una herramienta típica del "nuevo urbanismo". 
interesante" [arquitecto 2], pero que en la materialización del relato "venció la rapidez y la eficacia" [arquitecto 3]. "Los tiempos políticos no coinciden con los tiempos técnicos" ${ }^{29}$ [arquitecto 2] y es que "esta ciudad es lo más importante para el presidente [Correa]" [arquitecto 4]. La ciudad sigue levantándose a buen ritmo según los reportes oficiales, con la ayuda del gobierno de Corea del Sur, quien invierte en la construcción de edificios y ejecuta el plan a través de la compañía ConEcuaKor C.E. M. ${ }^{30}$

\section{Análisis socio-jurídico de los agravios suscitados por el proyecto}

Conocer el impacto social de la construcción de Yachay ha sido otro de los objetivos de investigación; de este modo nos propusimos entrevistar además a algunas personas afectadas: vecinos de las comunidades del ámbito del proyecto, representantes políticos y técnicos de los municipios de Urcuquí e Ibarra, propietarios de los terrenos expropiados y trabajadores agrícolas.

En nuestros contactos iniciales y casi accidentales con trabajadores de Yachay EP - previos a la reunión formal mencionada - advertimos en ellos una serie de gestos de incomodidad. El primero de éstos fue cuando preguntamos cómo se habían llevado a cabo los procesos de expropiación de los terrenos afectados. En este momento, el director de "relacionamiento comunitario" quien supuestamente debía ser uno de nuestros informantes clave - se levantó de la mesa y, visiblemente alterado, negó que pudiéramos acceder a este tipo de información; seguidamente, abandonó la sala. Nuestros otros dos interlocutores en la reunión se quedaron y nos hicieron notar sus suspicacias al preguntarnos si lo que queríamos hacer era "contrastar si en Yachay se desarrolla o no un urbanismo comunitario” [técnico Yachay EP 1].

Según el documento de Rendición de Cuentas de Yachay de 2014, la inversión total del proyecto está presupuestada en 1.041.182.639,45 dólares para el periodo de 2012-2017. Una de las quejas generales que hemos podido oír es que se destinan muchos recursos para la construcción de la nueva ciudad, mientras la mayoría de las comunidades afectadas aún no disponen de servicios básicos como alumbrado, alcantarillado, agua corriente o electricidad. Los habitantes de las seis comunidades afectadas, de un día para otro, sin previo aviso ni consulta, están viendo alterada y precarizada su forma de vida. ${ }^{31}$ Algunos de los vecinos afectados confían en que este proyecto traiga "desarrollo al

29 Mientras nos explicaba cómo "por cuestiones políticas" se contrató a empresas constructoras para ejecutar las calles cuando aún no habían terminado el diseño de los tramos de carreteras.

30 ConEcuaKor C.E.M. es la empresa ecuatoriano-coreana de construcción. Según la descripción de su sitio web oficial, es una "empresa de economía mixta hecha por el Cuerpo de Ingenieros del Ecuador y Cheong Hai Ingeniería y Construcción, para la realización de proyectos emblemáticos y estratégicos de Ecuador". Más información en < http://www.conecuakor.com/ > (última consulta en junio de 2018). 31 Las seis comunidades son: Mercedes, San Vicente, El Puente, Tapiapamba, San Antonio y Armas Tola. 
sector que ha sido uno de los más olvidados", ya que no dispone de "dispensario médico ni mucho menos transporte público". ${ }^{32}$ En medio de la opulencia del macroproyecto se impone la escasez y la incertidumbre para las familias de trabajadores, pequeños y medianos propietarios afectados. ${ }^{33}$

Por todo esto, el tema de la participación ciudadana fue sin duda el más discutible en la planificación de Yachay. Los jóvenes arquitectos entrevistados justificaban la inexistencia de participación diciendo que "allí no vivía gente", ya que las comunidades afectadas quedaban fuera del ámbito. Aun así, reconocían: "Usted no llega en una nave espacial y hace una ciudad, usted tiene que hacerla con la gente de allí. Ahora bien, allí no había gente", decía uno de los arquitectos [arquitecto 3]. Esto se contradecía con nuestras observaciones y con los datos ofrecidos por los técnicos municipales de participación ciudadana que hablan de unas 1500 familias de comuneros afectados, ya sea habitacional o laboralmente (entre 7000 y 10.000 personas).

La relación con las comunidades era un tema no resuelto y ciertamente controvertido. "Yachay EP no deja hablar con ellas ni [invertir] ahí, pero les ayuda porque se siente con la responsabilidad [...] Yo pretendía [organizar una planificación urbanística comunitaria] pero se frenó en el último momento" [arquitecto 2]. Lo que sí organizaron fueron mingas: uno de los arquitectos comentaba: "algunos fuimos a picar, levantar, cargar, ayudar... cosas pequeñas pero que al final generan cosas muy interesantes y conversas con la gente $[\ldots]$ con algunas personas sociables, amistosas, otras que les da miedo, incluso algunas que te pueden ofender... que te dicen: ¿qué haces aquí?" [arquitecto 4].

La primera expresión de malestar contra Yachay se produjo en enero de 2012 cuando a los vecinos y propietarios se les notificó la expropiación forzosa de sus tierras. ${ }^{34}$ La retórica oficial para justificar la expropiación en Urcuquí es que allí solo había propietarios latifundistas, pero esto no era para nada cierto. ${ }^{35}$ Los terrenos pertenecían aproximadamente a un centenar de propietarios y la mitad de los lotes tenían menos de cien hectáreas y, de esta mitad, una parte significativa menos de 15 hectáreas [abogado]. ${ }^{36}$ Esto no ha sido obstáculo - probablemente, todo lo contrario - para que la especulación sobre

32 "Seis comunidades reclaman por falta de empleo en Urcuquí", en Noticias Ecuador, TVN Ecuador, 24 de enero de 2014.

33 "Urcuquí se transformará en la Ciudad del Conocimiento", Diario El Norte, 19 de noviembre de 2011.

34 Así nos lo explicaron en el Gobierno Autónomo Descentralizado de Urcuquí. Ver también la noticia "Comuneros opuestos a venta de sus terrenos", Diario Hoy, 27 de enero de 2012.

35 Ver "Discordia por el valor de los predios para Yachay", Diario Sierra Norte, 15 de junio de 2012

36 La inmensa mayoría de pequeños propietarios habían accedido a 1 hectárea de tierra de cultivo como parte de su jubilación, siguiendo un ritual de la época colonial llamado guasipungo. 
el suelo en el perímetro de Yachay haya alcanzado límites insospechados. Se calcula que si una hectárea costaba antes del inicio del proyecto entre $600 \mathrm{y}$ 800 dólares, en 2014 estaría superando los 100.000 y que en el centro urbano los precios se habían multiplicado por diez. ${ }^{37}$

Las fértiles tierras de cultivo, ahora propiedad del Estado, no han sido cedidas ni concesionadas a los trabajadores sin tierra. ${ }^{38}$ Éstos se quejan de que les prohíben trabajar las granjas avícolas, el invernadero de amapolas o las tierras expropiadas por Yachay que tienen a unos pocos metros de distancia de sus casas. Como compensación se les forma y no se les deja otra salida que la de realizar trabajos de albañilería, pasando a depender de la demanda de obreros poco cualificados para la construcción. A esto cabe añadir que, como nos hacían saber algunos de los albañiles, auxiliares de limpieza, jardineros o guardias de seguridad, sufren retrasos de hasta tres meses o directamente impagos en sus nuevos trabajos, cuando no rescisiones de contratos [técnico municipal y vecino 2]. Muchas de las tareas de la construcción de la ciudad son externalizadas, hecho que facilita que los responsables de Yachay EP rehúyan responder a la demanda de explicaciones como la que les hizo la presidenta de una de las comunidades al denunciar que "de un día para otro habían despedido a un centenar de guardias de seguridad [todos vecinos afectados por la construcción de Yachay]" [vecina 1]. ${ }^{39}$

Por el momento, sólo existe una comunidad amenazada con ser desalojada íntegramente. Se trata de Tapiabamba, donde viven, en su mayoría, descendientes de afroecuatorianos desde hace más de 130 años. Son 72 familias. Los miembros de mayor edad no quieren abandonar las casas donde han vivido desde hace varias generaciones, mientras que los más jóvenes, según nos contaron, confían en ser reubicados "en apartamentos nuevos gratuitos y dentro del perímetro de Yachay" - particular éste que Yachay EP no desmiente pero Immobiliar, la empresa pública encargada de las expropiaciones, ${ }^{40}$ descarta

37 La prensa local se hizo eco de este aumento de precios que en 2012 ya alcanzaba el 100\%. Ver la noticia "Hay un incremento en el costo de terrenos en Urcuquí", La Hora, 16 de mayo de 2012.

38 Entre varios ejemplos, cabe destacar el que me expuso el presidente de la Feconic (Federación de Comunidades y Organizaciones Negras de Imbabura y Carchi): Yachay EP les niega alquilarles 300 hectáreas (de las 4489) para ser trabajadas por los vecinos de las comunidades afectadas.

39 Nos explicó cómo Yachay EP había dejado de ser la encargada de las contrataciones y ahora dependían directamente de la empresa privada de seguridad Delta. Como presidenta, las familias acudían a ella para que "hiciera algo" y, mientras tanto, los técnicos de Yachay EP - ya sin responsabilidad formal le prometían que les volverían a contratar. Ella nos comentaba "yo no me lo creo". Y es que otro de los miedos que los vecinos expresan en las entrevistas es el de los despidos por falta de presupuesto y que la ciudad "se quede a medias". Entonces ya no habrá vuelta atrás, decía la entrevistada, no podrán trabajar en la producción agrícola ni las mujeres limpiar en las haciendas [vecina 1].

40 Así es como comúnmente se conoce el Servicio de Gestión Inmobiliaria del Sector Público, la empresa pública encargada de les expropiaciones en Yachay. 
absolutamente. ${ }^{41}$ Los vecinos responden que, si no se les compensa por los daños que están sufriendo, "habrá guerra" [vecino 3].

Así pues, se está vulnerando el punto 7 del artículo 57 del capítulo $4 .{ }^{\circ}$ de la Constitución ecuatoriana, que obliga a ofrecer "indemnizaciones por los perjuicios sociales, culturales y ambientales que les cause" la construcción de la nueva ciudad, ya que esto no se ha producido. El derecho a la reubicación y compensación de los afectados por Yachay es igualmente ignorado en cualquiera de los comunicados oficiales de Yachay EP y en el propio master plan de la nueva ciudad. Para la realización del proyecto se soslayan principios constitucionales como el de la obligatoriedad de realizar una "consulta previa, libre e informada sobre planes y programas de prospección, explotación y comercialización de recursos no renovables que se encuentren en sus tierras y que puedan afectarles ambiental o culturalmente". Para más inri, cabe tener presente que el elogiado PNBV contempla en su objetivo número uno que:

"Se debe contar con una participación ciudadana que asuma el reto de poner en marcha el cambio de la matriz productiva en cada uno de los territorios; dicho de otra manera, se requiere una ciudadanía que anhele y se apasione con la idea de colocar en el mundo no solo materias primas, sino también conocimiento, servicios y bienes hechos en el Ecuador. Se necesita de una ciudadanía que no descanse hasta lograr el cierre de las brechas que diferencian y separan a los ecuatorianos y ecuatorianas" (Senplades 2013: 38).

Lo observado muestra hasta qué punto se vulneran tanto principios constitucionales como los esperanzadores objetivos recogidos en este plan rector que debía ser el PNBV. Mientras, se ha indemnizado sólo a alguno de los empleados de las haciendas - gracias a la intervención del Ministerio de Trabajo -, pero no se ha compensado por los perjuicios sufridos, pasados, presentes y venideros según prevé la Constitución. Por otro lado, a la demanda de "diálogo" exigida por el municipio, los pequeños y medianos propietarios y las comunidades afectadas, Yachay EP responde con varios años de silencio y ausencia total

41 Esto provocó otra de las manifestaciones de los comuneros [técnica municipal 1]. Y es que, según nos explicaron representantes de los comuneros afectados, se ha firmado un convenio entre las comunidades y Yachay EP que implica que ningún vecino puede quedarse sin trabajo o ser desplazado. El abogado de los mismos se ocupó de desmentírnoslo. El convenio se firmó entre las comunidades y Yachay EP, pero es Immobiliar la encargada de las expropiaciones y para ella el convenio no implica compromiso jurídico alguno. Según la presidenta de una de las comunidades, "el acuerdo es sólo verbal" y alerta que "a otras comunidades les han vuelto a decir [que pueden ser expropiadas]". Acaba la entrevista diciéndonos: "Las seis comunidades juntas somos invencibles, pero al final nos sacarán [del perímetro de Yachay]” [vecina 1]. 
de conversaciones sobre las cuestiones-clave: expropiaciones, desplazamientos, desahucios, participación o indemnizaciones.

\section{La gobernanza del malestar}

Tanto vecinos como técnicos del nuevo equipo de gobierno del ayuntamiento de San Miguel de Urcuquí nos contaron que Yachay EP comenzó a atender a las comunidades en respuesta a la primera movilización de protesta. Según nos explicaron, en la recién electa alcaldía de Urcuquí en julio de 2014, la primera manifestación de protesta contra la construcción de Yachay en enero de 2012 comportó el asalto al edificio municipal y agresiones a las autoridades por parte de los comuneros. ${ }^{42}$ Dos años después de las movilizaciones, la líder de estas protestas fue contratada en el nuevo gobierno municipal y nombrada concejala de las seis comunidades. Según los técnicos municipales, Yachay EP dividió y enfrentó a los afectados: primero separando a los grandes propietarios de los medianos y pequeños y a éstos de los asalariados y jornaleros; luego, imponiendo Yachay EP e Inmobiliar las negociaciones individualmente y rechazando las colectivas.

Esta división de los afectados se ha apoyado en un proceso de cooptación y clientelización de los representantes de las seis comunidades. Sabemos que se ha reclutado a líderes de las comunidades ofreciéndoles trabajos espurios a cambio de su confianza y tranquilidad respecto a Yachay. Los técnicos municipales opinan que la cooptación ha debilitado e incluso hecho desaparecer las protestas. ${ }^{43}$ Estiman que su papel como técnicos municipales, así como el "departamento de relacionamiento comunitario" de Yachay EP, es contener las quejas y el malestar de los afectados dentro de unos límites tolerables y, especialmente, evitar que aparezca cualquier noticia crítica en prensa respecto al "proyecto emblemático de la revolución ciudadana". ${ }^{44}$ El programa "Mi Barrio Lindo" parece ser el buque insignia de este departamento. En él se puede comprobar la folklorización y licuación política a la que se ha sometido un pilar básico de la nueva Constitución ecuatoriana como es la participación

42 Ver "Así se transformará en la Ciudad del Conocimiento", Diario El Norte, 19 de noviembre de 2011. Nos lo explicaron en el Gobierno Autónomo Descentralizado de Urcuquí. Ver también la noticia "Comuneros opuestos a venta de sus terrenos", Diario Hoy, 27 de enero de 2012, o "Seis comunidades reclaman por falta de empleo en Urcuquí", en Noticias Ecuador, TVN Ecuador, 24 de enero de 2014. Ninguna de estas noticias es accesible ahora desde Internet.

43 La penúltima movilización de la que tuvimos noticia fue donde los trabajadores reclamaban a la empresa ConEcuaKor el compromiso del salario de $12 \$$ día en lugar del que estaban recibiendo, de 8 \$día.

44 Así nos lo explicó una comunera: "tienen miedo que algo de lo que está pasando con nosotros salga en la prensa". Efectivamente, como ya se ha dicho, es extremadamente difícil encontrar artículos en prensa cuestionando el proyecto Yachay. Comprobamos, por ejemplo, que, aunque se hubiesen publicado noticas críticas sobre el proyecto, éstas habían sido eliminadas de los sitios web y solo las podíamos localizar en las hemerotecas de los respectivos diarios. 
ciudadana (Becker 2013; De la Torre 2013, 2014; Schneider y Welp 2011; Torres Vinueza 2014). Además se puede contrastar la tergiversación de la participación hablando con los comuneros y también buscando en el sitio web de Yachay sobre "relacionamiento comunitario". ${ }^{45}$ Una de las vecinas entrevistadas nos explicaba que el proyecto se centraba de manera casi exclusiva en la organización de las citadas "mingas", resultando una especie de "bálsamo para tener a la gente tranquila" [vecino l].

Los vecinos nos explican cómo los técnicos de participación de Yachay EP les han confesado que, contradictoriamente, ellos no están allí para hacer "relacionamiento comunitario sino para cumplir órdenes". Aunque esta respuesta pudiera sonar a analogía gratuita con un régimen totalizante, advertimos pronto que lamentablemente no era así. El 9 de septiembre de 2014, el gerente general de Yachay EP, Héctor Rodríguez, ofertaba de una manera ciertamente desacomplejada en su muro personal de la popular red social Facebook puestos para trabajar en la empresa pública:

"ingenieros civiles con maestría, experiencia en administración de proyectos de infraestructura, ALINEADOS políticamente, experiencia en el sector público, proactivos y con disponibilidad para trabajar en territorio (Urcuquí) x interno sus cv para entrevistas y proceso de selección de perfiles." 46

Los técnicos municipales critican frontalmente la ausencia total de participación de los afectados en el proceso de diseño y construcción de la nueva ciudad, el regateo en las indemnizaciones o la falta de inversión en servicios básicos para las comunidades [técnico 2]. Aun así, no se atreven a denunciarlo legalmente por miedo a represalias de su partido. ${ }^{47}$ Nos confiesan igualmente

45 En la web apenas se puede encontrar alguna nota al respecto invitando a los vecinos a colaborar con "el fortalecimiento y crecimiento de su comunidad". Ver "La Merced y Santa Rosa, comunidades activas en la minga 'Mi Barrio Lindo'”, sitio oficial de Yachay, en < http://www.yachay.gob.ec/tag/minga -yachay/ > (última consulta en junio de 2018). Otro ejemplo de la distancia entre representación o discurso y práctica es la noticia aparecida en el mismo sitio web "Una Ciudad Verde que se construye con el aporte y empoderamiento de la ciudadanía en el Ecuador: Yachay", < http://www.yachay.gob.ec/unaciudad-verde-que-se-construye-en-el-ecuador-yachay/ > (última consulta en junio de 2018). Solamente el titular convoca "empoderamiento" y "ciudadanía" para no explicar nada al respecto en el cuerpo de la noticia.

46 Transcripción literal sin modificaciones. Las mayúsculas son suyas.

47 Así nos lo hicieron notar los responsables de participación del municipio de Urcuquí. Cabe recordar que Urcuquí fue el único municipio de Imbabura que mantuvo en la alcaldía el partido del presidente Rafael Correa. El caso de la elección del nuevo alcalde de Urcuquí es muy elocuente al respecto. Julio Cruz ganó las elecciones municipales de 2014. Él era el candidato de la oposición, pero semanas antes de poner las urnas, Alianza País le hizo una oferta para que se presentase con ellos. Al ganar las elecciones, sus técnicos municipales y él mismo, nos insistirán que no pueden cuestionar el proyecto de Yachay porque es un proyecto de Rafael Correa, máxima autoridad de su partido. 
que, desde la gerencia de Yachay EP, el modelo que se quiere desarrollar es el de "ciudad privada". Y es que, según las autoridades, para que estas buenas intenciones de promesas de un nuevo mundo en ciernes se hagan realidad, a la nueva ciudad se le deben otorgar poderes excepcionales. En esto consiste la declaración de las de 4489 hectáreas destinadas a Yachay como Zona Especial de Desarrollo Económico (ZEDE). A estas zonas se les conoce también como "ciudades libres", entre otras cosas porque los territorios escogidos para su construcción son definidos previamente como "vacant or virgin lands". Además de ser escogidas por la poca resistencia vecinal que se supone al estar poco habitadas, se considera que las "free cities" pueden ser la solución a países "plagados de violencia, corrupción, ineficiencia y complacencia". ${ }^{8}$ Además de la excepcionalidad fiscal y otras ventajas para atraer capital e inversiones, esto significa que la zona no se somete a ningún órgano democráticamente electo. Tal y como nos explicó un guía en nuestra primera visita a la nueva ciudad, "Yachay EP es [a todos los efectos] nuestro ayuntamiento".

En este ambiente castrense - y castrante -, un empleado público de Yachay EP es capaz de reconocernos - sottovoce - que ellos ven Yachay como la materialización de un nuevo "colonialismo urbano [...] donde antes estaban los grandes hacendados ahora está Yachay EP". Nos ilustran igualmente de las contradicciones con las que desempeñan su labor cuando reconocen a los presidentes de las comunidades que "si no estuvieran a sueldo del gobierno, estarían de su lado" y que "deben estar unidos porque el proyecto que va a venir les va a aplastar" [vecina 1$]$.

A MODO DE CONCLUSIÓN:

YACHAY COMO PARADIGMA DEL CONTROL DE LA PARTICIPACIÓN Y DEL CONOCIMIENTO EN LOS MACROPROYECTOS URBANÍSTICOS

Este artículo ha añadido al debate sobre las "smart cities" o "cities from scratch" (Carvalho 2015; Datta 2015; Luque-Ayala y Marvin 2015; Shwayri 2013), un vector no siempre destacado: y es que las utopías planificadas requieren de un control de la información y, por tanto, de las investigaciones independientes que se lleven a cabo. Se trata de ciudades "sin historia" (Murray 2015) o, mejor dicho, ciudades donde se ha hecho un borrado sistemático de todo aquello que podría poner en peligro (o en contradicción) "el milagro del renacer urbano de la utopía espacial” (Navas Perrone 2016: 2). La lucha contra cualquier manifestación de conflicto que pueda perturbar la legibilidad absoluta del espacio es la tarea que asumen los técnicos de Yachay EP y las personas encargadas de

48 Ver Alex Clark-Youngblood, "Bleeding heart in Honduras: give 'free cities' a chance", The PanAm Post, 24 de abril de 2014. 
la construcción de Yachay para someter todas las preexistencias a un modelo de "ciudad ideal".

En este sentido, hemos visto cómo tratan de imponer una identidad colectiva que aparente cohesión y rechace cualquier forma de conflicto social, que abrace el consenso y colabore en promover la imagen de una ciudad segura y apaciguada, símbolo de la ilusión de todo un país. En Yachay hemos comprobado cómo esta búsqueda de consenso se ha visto favorecida silenciando las críticas hacia el proyecto en los medios de comunicación de masas, así como por la sobreproducción de material promocional (videos, revistas, dosieres, anuncios publicitarios) y de "construcción de imaginario", y por la gran cantidad de eventos sociales y culturales organizados y firmados por Yachay EP. ${ }^{49}$ Los estudiantes, profesores e investigadores de la "familia Yachay" están compartiendo la experiencia de estrenar una ciudad: pero no una ciudad cualquiera sino la ciudad que cambiará el futuro del país. De aquí la recurrencia a elementos no incómodos - como podría ser la leyenda de las brujas de Urcuquí - y no a los controvertidos como son las comunidades que se quiebran dentro del ámbito afectado que sí podrían entorpecer la construcción rápida e irreversible de la nueva ciudad.

Como ya hemos dicho, del abrazo de "lo nuevo" se desprende una visión negativa de lo existente y que contiene un mensaje implícito de rechazo y abandono a su posible renovación o mejora. Se propone la construcción de una ciudad nueva sin tratar de mejorar las condiciones de las ciudades y asentamientos existentes, los cuales sufren problemas graves de urbanización, pobreza e inequidad, entre otros. Lo mismo ocurre en el ámbito académico: en lugar de mejorar la red de centros educativos existentes, se destinan ingentes recursos públicos a crear una nueva universidad experimental (Villavicencio 2014; Blanco 2013). En este sentido, Yachay, al igual que el resto de utopías espaciales, se auto-presenta como una experimentación para posteriores desarrollos urbanos, aunque es - y será - una excepción (Shelton, Zook y Wiig 2015). Por último, frente a los cánones propuestos por el PNBV y recogidos por los jóvenes urbanistas ecuatorianos, se impone una lógica planificadora y constructiva más parecida al "fast urbanism" (Herzog 2006) que a lo que debía ser el ilusionante "urbanismo del buen vivir".

Otra de las contradicciones de la utopía espacial es el determinismo espacial en el que se basa. En Yachay, hemos podido observar cómo el equipo de arquitectos ecuatorianos que trabajó en los inicios del proyecto elaboró un relato que legitimó - y en parte lo sigue haciendo - la dudosa convicción de

49 Ver en Twitter la gran cantidad de mensajes, imágenes y eslóganes que cuelga el usuario @CiudadYachay (de Yachay EP) y los hashtag que crean como \#YachayEsMiSueño; \#EstoEsYachay o \#ViveYachay; ver "Este feriado vive las expresiones del arte, la danza y la cultura" (\#Carnavales2016 \#ViveYachay \#ViveEcuador), en < https://t.co/Nvgme9uOVL > (última consulta en junio de 2018). 
crear una "ciudad in vitro". Dicha concepción, desde el laboratorio proyectual, obedece a un determinismo espacial mediante el cual el proyectista "dota de cierta elocuencia al plano, que se encarnará posteriormente en los usuarios como una suerte de hechizo para hacer florecer mágicamente formas barriales de sociabilidad" (Navas Perrone 2016: 9). Un determinismo espacial que lleva implícito una simplificación del funcionamiento de la ciudad y un afán de controlar todo lo que en ella sucede. En las utopías espaciales se minimizan - si no se eliminan totalmente - los problemas que típicamente se asocian a la ciudad existente (conflictos, inseguridad, contaminación, desigualdad...) y se pretende una vida armoniosa, ordenada e igualitaria (Murray 2015); se obvian las características innatas de la vida urbana (imprevisibilidad, complejidad, conflictividad...) y se invoca a un orden social - y a veces moral - a través de la lógica, el orden, la eficiencia, la racionalidad y la funcionalidad espacial.

Como declaró el expulsado rector de Yachay Tech, Fernando Albericio, cualquier crítica, reflexión o investigación sobre el proyecto se convierte automáticamente en juicio negativo contra la Revolución Ciudadana. De ahí la imposibilidad de pensar en la "ciudad pensada para pensar". De ahí la actitud de los responsables de Yachay EP al negarnos tajantemente la entrada a Yachay y por tanto a nuestro campo de investigación. Y es que, tal y como este artículo ha mostrado, existen graves disonancias entre el relato de Yachay - como "una ciudad abierta, participativa" - y la planificación y construcción del "proyecto nacional más importante de los últimos cien años” que cuestionan frontalmente la consecución de los objetivos primeros del PNBV.

Debe ser por ello que quizás sea Yachay un caso paradigmático del abandono y la instrumentalización a la que el gobierno está sometiendo la participación ciudadana, una de las cinco funciones del Estado. En palabras de uno de los abogados de los afectados, la participación no ha existido y contra ella se ha impuesto con urgencia el plan de construcción de una ciudad en un territorio en el que la ciudadanía y sus derechos constitucionales parecen estorbar. La falta de participación es un error que está en el mismo nacimiento de la idea de construir una "ciudad del conocimiento" en Urcuquí. Los escasos investigadores que han podido elaborar, publicar y hacer circular algún texto de análisis crítico sobre Yachay alertan que no ha existido una coordinación con las demás universidades nacionales, ni públicas ni privadas, y señalan que no se contempla ni se consulta la industria nacional; denuncian igualmente que se obvian las iniciativas locales y de las comunidades y que ni siquiera se cuenta con la autoridad municipal de Urcuquí ni tampoco con la de la capital de la provincia de Imbabura, Ibarra (Sorkin 2014; Villavicencio 2014; Macías Vázquez y Alonso González 2016).

Concluimos aquí postulando que Yachay puede significar el proyecto que condensa más claramente las contradicciones entre la experiencia cotidiana 
económica y sociopolítica en Ecuador y la ola entusiasta de transformación social que debía significar la Revolución Ciudadana. Este particular lo hemos observado interpretando que el bloqueo de la participación ciudadana en tanto quinta función del Estado, así como la prohibición de la investigación, pueden tener en Yachay un ejemplo paradigmático y contradictorio con el marco jurídico y el espíritu de la Revolución Ciudadana. ${ }^{50}$ Hemos explicado este rechazo gubernamental al conocimiento y a la participación ciudadana en el macroproyecto en tanto condición sine qua non para la explotación política de la utopía urbanística, siendo no la única pero sí la más importante vertiente la canalización del entusiasmo colectivo en favor de los intereses de los planificadores y del partido en el gobierno. Creemos haber alcanzado el objetivo de estas páginas al desvelar lo que la utopía del espacio concibe como una tara a eliminar: el derecho a la ciudad y a la libre investigación académica.

Las tácticas defensivas paranoides de Yachay EP han intentado enterrar el fantasma de la participación en el nombre de una revolución que hace caso omiso de los vecinos y desacredita la investigación crítica. De esta manera, Yachay representa una utopía tecnológica en la medida en que habita en el reino del prospectivismo, la ingeniería social y la programación; consecuentemente, los intentos de materialización de este sueño urbano están siendo aplastados bajo el peso de sus muros reales y metafóricos, negando el derecho de los afectados y el de los investigadores a conocer Yachay, la "ciudad del conocimiento", la "ciudad del buen vivir".

50 La Constitución de Ecuador de 2008 es muy innovadora en muchos aspectos. Uno de los más destacados es que añade a los tradicionales tres poderes del Estado dos más, que aquí se llaman "función electoral" y "de transparencia y control social" que incluye el Consejo de la Participación Ciudadana y Control Social (Aparicio Wilhelmi 2008). 


\section{BIBLIOGRAFÍA}

APARICIO WILHELMI, Marco, 2008, "Derechos: enunciación y principios de aplicación”, en R. Ávila Santamaría, A. Grijalva Jiménez y R. Martínez Dalmau (comps.), Desafíos Constitucionales: La Constitución Ecuatoriana del 2008 en Perspectiva. Quito, Ministerio de Justicia y Derechos Humanos, 19-40.

BACK, Les, y Nirmal PUWAR, 2012, "A manifesto for live methods: provocations and capacities”, Sociological Review, 60 (sup. 1): 6-17, DOI: 10.1111/j.1467-954X.2012.02114.x.

BAQIR, Muhammad Naveed, y Yunus KATHAWALA, 2004, "Ba for knowledge cities: a futuristic technology model”, Journal of Knowledge Management, 8 (5): 83-95.

BECKER, Marc, 2013, “The stormy relations between Rafael Correa and social movements in Ecuador", Latin American Perspectives, 40 (3): 43-62, DOI: 10.1 177/0094582X13479305.

BLANCO, Julio José, 2013, "Yachay: ¿elefante blanco o joya de la corona?", Lancaster, University Management School, working paper.

BOX, Richard C., 2003, "Contradiction, utopia, and public administration", Administrative Theory and Praxis, 25 (2): 243-260.

BURRELL, Jenna, 2009, “The field site as a network: a strategy for locating ethnographic research", Field Methods, 21 (2): 181-199, DOI: 10.1177/1525822X08329699.

CARVALHO, Luís, 2015, "Smart cities from scratch? A socio-technical perspective", Cambridge Journal of Regions, Economy and Society, 8 (1): 43-60, DOI: 10.1093/cjres/rsu0 10.

CASTillo COllado, Martín, 2005, Aprendiendo con el Corazón: El Tejido Andino en la Educación Quechua. La Paz, PINSEIB/PROEIB-Andes/Plural Editores.

CHOAY, Françoise, 1997, The Rule and the Model: On the Theory of Architecture and Urbanism. Cambridge, MA, The MIT Press.

CLIFFORD, James, 1988, The Predicament of Culture: Twentieth-Century Ethnography, Literature, and Art. Cambridge, MA, Harvard University Press.

CUNHA, Neira Vieira da, et al. (comps.), 2015, Antropologia do Conflito Urbano: Conexões Rio -Barcelona. Rio de Janeiro, Lamparina.

DATTA, Ayona, 2015, "New urban utopias of postcolonial India: 'entrepreneurial urbanization' in Dholera smart city, Gujarat”, Dialogues in Human Geography, 5 (1): 3-22, DOI: $10.1177 / 2043820614565748$.

DE LA TORRE, Carlos, 2013, "In the name of the people: democratization, popular organizations, and populism in Venezuela, Bolivia, and Ecuador", European Review of Latin American and Caribbean Studies, 92: 27-48.

DE LA TORRE, Carlos, 2014, “The people, democracy, and authoritarianism in Rafael Correa's Ecuador", Constellations, 21 (4): 457-466, DOI: 10.1111/1467-8675.12117.

DEGEN, Monica, Clare MELHUISH, y Gillian ROSE, 2015, "Producing place atmospheres digitally: architecture, digital visualisation practices and the experience economy", Journal of Consumer Culture, 17 (1): 3-24, DOI: 10.1177/1469540515572238.

ESSER, Klaus, et al., 1996, Systemic Competitiveness: New Governance Patterns for Industrial Development. Londres y Portland, OR, Frank Cass/GDI.

ESTRADÉ, Antoni, 1986, "Paradoxes: apunts per a una espistemologia paradoxal en sociologia”, Papers: Revista de Sociologia, 26: 47-67, DOI: 10.5565/rev/papers/v26n0.1456.

HALPERN, Orit, et al., 2013, “Test-bed urbanism”, Public Culture, 25 (2): 272-306, DOI: 10.1215/08992363-2020602.

HARVEY, David, 2000, Spaces of Hope. Berkeley y Los Angeles, University of California Press. 
HARVEY, David, 2009, "Las grietas de la ciudad capitalista: entrevista con David Harvey", Revista Geográfica de América Central, 43: 109-1 17.

HERZOG, Lawrence A., 2006, "Fast urbanism and slow urbanism: globalization and public space in three Mexican cities", disponible en < http://www.lawrenceaherzog.com/wp-con tent/uploads/2016/01/chapterinjoneseditedbook06.pdf $>$.

HOLSTON, James, 1989, The Modernist City: An Anthropological Critique of Brasília. Chicago, IL, The University of Chicago Press.

HUME, Lynne, y Janet MULCOCK, 2004, Anthropologists in the Field: Cases in Participant Observation. Nueva York, Columbia University Press.

KOVATS-BERNAT, J. Christopher, 2002, "Negotiating dangerous fields: pragmatic strategies for fieldwork amid violence and terror", American Anthropologist, 104 (1): 208-222, DOI: 10.1525/aa.2002.104.1.208.

Lefebvre, Henri, 1976, Espacio y Política: El Derecho a la Ciudad - II: Historia, Ciencia, Sociedad. Barcelona, Península.

LEIRIS, Michel, 1995, L'Etnóleg Davant el Colonialisme. Barcelona, Icaria.

LIANG, Samuel Y., 2013, "Planning and its discontents: contradictions and continuities in remaking China's great cities, 1950-2010”, Urban History, 40 (3): 530-553, DOI: 10.101 7/S0963926812000752.

LUQUE-AYALA, Andrés, y Simon MARVIN, 2015, "Developing a critical understanding of smarturbanism?”,Urban Studies, 52 (12):2105-21 16,DOI: 10.1 177/0042098015577319.

MACÍAS VÁZQUEZ, A., y P. ALONSO GONZÁLEZ, 2016, "Between 'neodevelopmentalism' and 'postdevelopmentalism': towards a theory of a dispersed knowledge economy in Ecuador" Canadian Journal of Development Studies/Revue canadienne d'études du développement, 37 (1): 47-65, DOI: 10.1080/02255189.2016.1129940.

MACKEY, Danielle Marie, 2014, "I've seen all sorts of horrific things in my time. But none as detrimental to the country as this. U.S. conservatives are about to run a dangerous economic experiment in Honduras", New Republic, 15 de deciembre, disponible en $<$ https://newrepublic.com/article/120559/honduras-charter-cities-spearheaded-us-conse rvatives-libertarians $>$ (última consulta en junio de 2018).

MURRAY, Martin J., 2015, "Waterfall city (Johannesburg): privatized urbanism in extremis", Environment and Planning A: Economy and Space, 47 (3): 503-520, DOI: 10.1068/a 140038p. NAVAS PERRONE, María Gabriela, 2016, "La vocación utópica del urbanismo: el caso de la Vila Olímpica de Barcelona”, presentado en el XIV Coloquio Internacional de Geocrítica: Las Utopías y la Construcción de la Sociedad del Futuro, Barcelona, 2-7 de mayo.

PHILLIPS, Arthur, 2014, "Charter cities in Honduras? Are private cities the miracle cure for Honduras' surging violent crime, state violence and institutional disarray?", Open Democracy, 7 de enero, disponible en < https://www.opendemocracy.net/opensecurity/art hur-phillips/charter-cities-in-honduras $>$ (última consulta en junio de 2018).

POLLARD, Amy, 2009, "Field of screams: difficulty and ethnographic fieldwork", Anthropology Matters, 11 (2), disponible en < https:/www.anthropologymatters.com/index.php/a nth_ma tters/article/view/10/12 > (última consulta en junio de 2018).

SAHA, Deepanjan, y Joy SEN, 2016, "Understanding clustering in creative-knowledge cities: creative clusters in Kolkata, India”, GSTF Journal of Engineering Technology, 3-4: 33-38.

SCHNEIDER, Cecilia, y Yanina WELP, 201 1, “¿Transformación democrática o control político? Análisis comparado de la participación ciudadana institucional en América del Sur", Íconos: Revista de Ciencias Sociales, 40: 21-39. 
SENPLADES - SECRETARIA NACIONAL DE PLANIFICACION Y DESARROLLO, 2013, Plan Nacional de Desarrollo/Plan Nacional para el Buen Vivir 2013-2017. Quito, Secretaria Nacional de Planificacion y Desarrollo.

SHELTON, Taylor, ZOOK, Matthew, y Alan WIIG, 2015, “The 'actually existing smart city'”. Cambridge Journal of Regions, Economy and Society, 8 (1): 13-25, DOI: 10.1093/cjres/rsu 026.

SHWAYRI, Sofia T., 2013, "A model Korean ubiquitous eco-city? The politics of making Songdo", Journal of Urban Technology, 20 (1): 39-55, DOI: 10.1080/10630732.2012.7 35409 .

SOARES, Paulo Roberto Rodrigues, 2010, "Del presupuesto participativo a los megaproyectos: la producción del espacio urbano en Porto Alegre en el siglo XXI", Scripta Nova, XIV (331): 1-13.

SÖDERSTRÖM, Ola, Till PAASCHE, y Francisco KLAUSER, 2014, "Smart cities as corporate storytelling”, City, 18 (3): 307-320, DOI: 10.1080/13604813.2014.906716.

SORKIN, Michael, 2014, "Learning from Yachay", The Architectural Review, 235 (1405): 25,4 .

SPANN, Michael, 2014, "Charter cities and development: examining a paradox", en Heloise Weber (comp.), The Politics of Development: A Survey. Abingdon, Routledge, 167-192.

TORRES VINUEZA, Jorge, 2014, El Gobierno Participativo: Estudio sobre el Concepto de Participación Ciudadana en la Constitución de 2008. S.1., s.n.

VILlAVICENCIO, Arturo, 2014, Innovación, Matriz Productiva y Universidad: Por Qué Yachay Es Una Estrategia Equivocada. Quito, Corporación Editora Nacional.

VILLAVICENCIO, Arturo, 2016, "Yachay: la costosa promesa redentora", Universidad y Sociedad: Foro Ecuador, 25 de mayo, disponible en < https://universidadsociedadec.wordpress. com/2016/05/26/yachay-la-costosa-promesa-redentora/ > (última consulta en junio de 2018).

YUlE, Marcos, 1999, Nasa üus yaht’n u’hun’i. Bogotá, Proyecto Nasa Toribio/PEBIN.

Receção da versão original / Original version Receção da versão revista / Revised version Aceitação / Accepted
$2016 / 12 / 11$

$2017 / 07 / 04$

$2018 / 05 / 15$ 